\title{
CUIDADO PARENTAL A UNA ESCUELA DE RENACUAJOS EN Leptodactylus petersii (STEINDACHNER, 1864) (ANURA, LEPTODACTYLIDAE) EN LAAMAZONIA PERUANA
}

\author{
Víctor R. Morales ${ }^{1}$ \\ Caroll Landauro ${ }^{1}$ \\ Reginald B. Cocroft ${ }^{2}$
}

\begin{abstract}
RESUMEN
El cuidado parental es la actividad de cuidar a los neonatos o crías por parte de la madre, el padre o ambos. Esta actividad que no es tan común en anfibios la realizan algunas familias con diversas modalidades. Se observó el cuidado parental de una hembra de Leptodactylus petersii a una escuela de sus renacuajos en un pantano temporal en la amazonia sur del Perú. La hembra realizaba movimientos de llamado para formar la escuela y la siguiera, sin embargo, estos permanecían, a veces, inmóviles y no acataban el llamado de la hembra.
\end{abstract}

Palabras claves: Cuidado parental, Leptodactylus petersii, renacuajos.

\section{SUMMARY}

Parental care is the activity to care for the newborns or young for the mother, father or both. This activity that is not than common in amphibians but some families do it with different modalities. We observed parental care of Leptodactylus petersii female to a school of her tadpoles in a temporary swamp in the South Amazonia of Peru. The female made call movements to form the school and follow her; nevertheless, they sometimes remained inmovables and did not obey the call of the female.

Key words: Parental care, Leptodactylus petersii, tadpoles.

\section{INTRODUCCION}

La actividad de cuidar a los neonatos o crías por la madre o el padre o por ambos es lo que se denomina «cuidado parental». Entonces, el cuidado parental en anfibios no es tan diverso como en el caso de aves y mamíferos. A pesar de la poca diversidad de cuidado parental en anfibios, muchas familias realizan esta actividad de forma más compleja. (McDiarmid, 1978).

Así, se conocen diversas modalidades de cuidado parental en anfibios, como es el caso de proteger a las larvas en espuma (Ej. la mayoría de leptodactílidos); llevar a las larvas en la espalda (Ej. los dendrobátidos); depositar los huevos en una marsupia dorsal (Ej. algunos hílidos); tragarse los huevos y estos se desarrollen en el estomago (Ej. algunos Racophoridos); poner los huevos en gelatina sobre las hojas u otro sustrato (Ej. algunos hílidos, leptodactílidos y bufónidos ) y mantener las larvas agrupadas en una escuela (Ej. algunos leptodactílidos e hílidos). Esta última modalidad es una actividad rara en anfibios, ya que, solo algunas especies la realizan como el caso de Leptodactylus bolivianus, cuya escuela de renacuajos formaron un paquete denso con individuos orientados en la misma dirección y fueron guiados con movimientos lentos de la hembra que hizo en el agua (Well y Bard, 1988). En Leptodactylus ocellatus la hembra permaneció con

\footnotetext{
$1_{1}$ Museo de Historia Natural, Universidad Ricardo Palma, Av. Benavides 5440, Apartado Postal 18-01, Urb. Las Gardenias, Surco, Perú.

2 Division of Biological Sciences, University of Missouri-Columbia, Columbia, MO, 65211, USA.
} 
la escuela en todo su desarrollo, acompañándolos día y noche hasta la metamorfosis (Vaz- Ferreira y Gehrau, 1975). A parte de los leptodactílidos, en la famila Hylidae también se reporta la modalidad de formar escuelas, como el caso de Hyla semilineata fue muy común observar escuelas de renacuajos tanto en el estado natural como en cautiverio y presento tres tipos de escuelas: densas, débiles y desplazadas (Heursel y Haddad, 2002). La escuela de Xenopus laevis tiene mas organización, ya que, los renacuajos emplean su visión y reconocer las lineas laterales de sus vecinos y así los renacuajos se mueven en paralelo (Katz et al. 1981). Sea ha sugerido que la modalidad de que algunas especies hagan escuelas de renacuajos fue como un comportamiento de protección anti depredador (Wassensug, 1873 y Waldman, 1982). En el presente trabajo reportamos un comportamiento de cuidado parental de una hembra de Leptodactylus petersii a una escuela de renacuajos.

\section{MATERIAL Y METODOS}

Se observo el cuidado parental sobre la escuela de renacuajos de Leptodactylus petersii en un pantano temporal a $500 \mathrm{~m}$, aproximadamente, sobre la trocha Laguna Chica del área del Albergue de Explore's Inn, en la Reserva Nacional de Tambopata, Provincia de Tambopata, Departamento de Madre de Dios. Se observaron cinco hembras de L. petersii, cada una con sus respectivas escuelas, durante la noche (20:00 a 22:00 horas) entre el 4 y 5 de diciembre de 1990 .

\section{RESULTADOS}

De las cinco hembras con escuela, solamente se describió el comportamiento de una hembra; ya que al mismo tiempo las otras hembras también hacían sus movimientos estereotipados de guiar a las escuelas.

Así, el 4 de diciembre se observo el comportamiento de la hembra A con su escuela (Fig. 1) durante una hora y 15 minutos. (1) 20:45 horas la escuela se movió de 3 a 4 m hacia el punto dos después que la hembra hizo cuatro movimientos; (2) 20:51 hrs. la 9 \& hace 8 golpes y se movió $6 \mathrm{~cm}$, allí tanto la escuela como la hembra se quedaron inmóviles; (3) a las 21:04 la $\& \&$ da un aviso y los renacuajos se escondieron y se alojaron, no hubo un movimiento de llamado; (4) a las 21:09 la 9 no hace nada y los renacuajos se acercaron de 6-8 cm. de ella; (5) a las 21:11, la 9 ataco a un insecto acuático; a las 21:15 no se visualiza a la escuela; (6) a las 21:18 se acerca otra 9 , y la primera ९ hizo 14 golpes, moviéndose $1 \mathrm{~cm}$.; (7) a las 21:22, la \& da otra señal de aviso, haciendo 5 golpes y luego golpes de 2 en 2; a las 21:24 hay mas señales de aviso, con golpes entre débiles y fuertes que duraron 4.3 segundos, recuperando así a la escuela; a las 21:25 la 9 da otro aviso y los renacuajos otra vez se juntaron a ella; (8) a las 21:26 la 9 se mueve 3 cm.; (9) a las 21:30 hubieron golpes entre débiles y fuertes, y los renacuajos no se movieron, la $९$ avanza de 7-8 cm.; (10) a las 21:33 hubieron 5 golpes hechos por la 9 que luego volteo y los renacuajos se acercan a $4 \mathrm{~cm}$. de ella, luego esta se va.; a las 21:47 la 9 sale; (11) a las 21:50 hace 2 golpes alejándose $10 \mathrm{~cm}$.; (12) dos minutos después - 21:52 0- se aleja $30 \mathrm{~cm}$.; (13) y dos minutos mas tarde regresa $10 \mathrm{~cm}$., y los renacuajos están en un solo lugar; (14) la @ hace otros cinco golpes entre cortos y largos para luego voltear y los renacuajos no se movieron; (15) a las 21:57 los renacuajos se acercan a la $\$$ y esta hace 7 golpes y luego golpes entre débiles y fuertes, haciendo que los renacuajos se acerquen $10 \mathrm{~cm}$.; (16) los renacuajos se dispersan alrededor de ella y cuando esta se mueve, los renacuajos vuelven a formar la escuela; a las 22:01se realizan 7 golpes y otros mas entre débiles y fuertes, los renacuajos están $10 \mathrm{~cm}$. dispersos de la १, luego esta se mueve y los renacuajos se juntan; (17) a las 22:04 la 9 se acerca $3 \mathrm{~cm}$. de la escuela, haciendo golpes entre débiles y fuertes, moviéndose a $15 \mathrm{~cm}$. y los renacuajos no se movieron; (18) a las 22:08 otra vez hace 6 golpes; a ;las 23:24 la escuela se acerca a $30 \mathrm{~cm}$. de ella; cuatro minutos mas tarde la $९$ da otra señal de aviso haciendo 19 golpes, moviéndose $4 \mathrm{~cm}$., luego hace 3 golpes mas, nada hacia los renacuajos y se aleja de ellos $10 \mathrm{~cm}$.

El tercer día de investigación 15/12/1990, a las 18:51 una $९$ 6 se acerca a la escuela de $8-10 \mathrm{~cm}$.; a las 19:06 la ९ junto a la escuela, esta ultima se mueve 10 cm. +/- por 2 minutos, los renacuajos siguen el camino de la ९; a las 19:14 la ९ se mueve para comer y la escuela se mueve a $2 \mathrm{~cm}$. de ella.

A las 22:02 una 9 en una $1^{\circ}$ frecuencia se aleja 10 $\mathrm{cm}$. de la escuela, en una $2^{0}$ frecuencia, se aleja 2 $\mathrm{cm}$., en la $3^{0}$ se aleja $3 \mathrm{~cm}$.; a las 22:10 en una $1^{0}$ frecuencia la escuela se acerca $6 \mathrm{~cm}$. de la \%, en la $2^{0}$ frecuencia la escuela se agrupa y se acercan a la s.

A las 22:15 en una $3^{0}$ frecuencia los renacuajos se acercan rápido a la 9 , en la $4^{0}$ frecuencia la escuela se agrupa y se acerca a $5 \mathrm{~cm}$. de la 9 .

A las 22:22 la escuela se movió $6 \mathrm{~cm}$.; en una $5^{0}$ los renacuajos se acercaron de $4-5 \mathrm{~cm}$. de la 9 , en la $6^{0}$ los renacuajos se acercaron la misma distancia agrupados, en la $7^{0}$ la escuela agrupada se acerco 5$6 \mathrm{~cm}$. de la 9; en la $8^{0}$ la escuela se acerco $10 \mathrm{~cm}$., en la $9^{0}$ se acerco $20 \mathrm{~cm}$. y ya estaba agitada, en una $10^{\circ}$ la escuela se acerco $15 \mathrm{~cm}$. de la 9 , en la siguiente frecuencia esta se acerco $30 \mathrm{~cm}$., moviéndose hacia el lado de la ९; en la $12^{\circ}$ la escuela se acerco $10 \mathrm{~cm}$., 
acercándose por debajo de la hojarasca; en la $13^{0}$ la escuela se acerco $20 \mathrm{~cm}$. de la \&, quedándose intactos y en la $14^{0}$ la escuela se volvió a acercar $10 \mathrm{~cm}$.

\section{DISCUSIÓN}

La funcion del comportamiento en la escuela de renacuajos ha sido discutida por varios autores (Wassersug, 1973; Waldman, 1982, Guilford, 1988) y las ventajas más probables para este comportamiento facilitarían la adquisición del alimento y disminuiría el riesgo de depredación.

La escuela de renacuajos de Leptodactylus petersii formaron escuela en determinados momentos, pero la mayor parte del tiempo los renacuajos permanecían inmóviles o seguían a la hembra sin coordinación de tiempos, como si lo hay en Leptodactylus bolivianus (Well y Bard, 1988). Entonces, el comportamiento en $L$. petersii indica que la escuela formada no era polarizada y durante toda la observación realizada estos no eran obedientes y se acercaban a la hembra pocas veces. Esto puede deberse a que en ese día habían cinco hembras con escuelas y la incidencia de depredadores fue muy baja.

Este reporte da a entender que las hembras realizaban movimientos de llamado, a lo que la escuela sentía este llamado y seguía a la hembra en un acto de obediencia como en $H$. semilineata (Heursel y Haddad, 2002) y L. bolivianus (Well y Bard, 1988), no obstante la escuela de Leptodactylus petersii no acataban los movimientos de llamado de la hembra, por lo que esta se alejaba y los renacuajos no siempre la seguían.

\section{AGRADECIMIENTOS}

A Max Günter, por permitirnos la estancia en el albergue Explorer Inn para la realización de este trabajo. A Mercedes Gonzáles, directora del Museo de Historia Natural de la Universidad Ricardo Palma, por la ayuda en las investigación.

\section{LITERATURA CITADA}

BEISWENGER, R.E. 1975. Structure and function in aggregations of tadpoles of the American Toad, Bufo americanus. Herpetologica 31:222-233

BEISWENGER, R.E. 1977. Diel Patterns of aggregative behavior in tadpoles of Bufo americanus, in relation to light and temperature. Ecology 58:98-108

CALDWELL, J. P. 1989. Structure and behavior of Hyla geographica tadpole schools, with comments on classification of group behavior in tadpoles. Copeia, Lawrence, 1989:938-950.

CALDWELL, J. P.; Thorp, J. H. \& Jervey, T. O. 1980. Predator-prey relationships among larval dragonflies, salamanders, and frogs. Oecologia, Berlin, 46:285-289.

DUELLMAN, W. E. \& Lescure, J. 1973. Life history and ecology of the hylid frog Osteocephalus taurinus with observations on larval behavior. Occas. Pap. Mus. Nat. Hist. Univ. Kansas, Lawrence, 13:1-12.

WALDMAN, B. 1982. Sibling association among schooling toad tadpoles: Field evidence and implications. Anim. Behav., London, 30:700-713.

WASSERSUG, R. 1973. Aspects of social behaviour in anuran larvae. In: VIAL, J. L. ed. Evolutionary biology of the anurans. Columbia, University of Missouri. p. 273-297.

GUILFORD, T. 1988. The evolution of conspicuous coloration. Am. Nat., Chicago, 131:7-21. 
Figura 1.- Desplazamiento de la hembra (línea sólida) y de la escuela de renacuajos (línea puntiaguda) de Leptodactylus petersii durante el cuidado parental. Los números en círculo son las estaciones de movimiento de la hembra; las letras son las estaciones de movimiento de la escuela de renacuajos. Para cada estación de la hembra se asocian los movimientos de señales que hace ésta; la distancia de desplazamiento de la hembra se detalla entre cada estación (explicación dentro del texto).

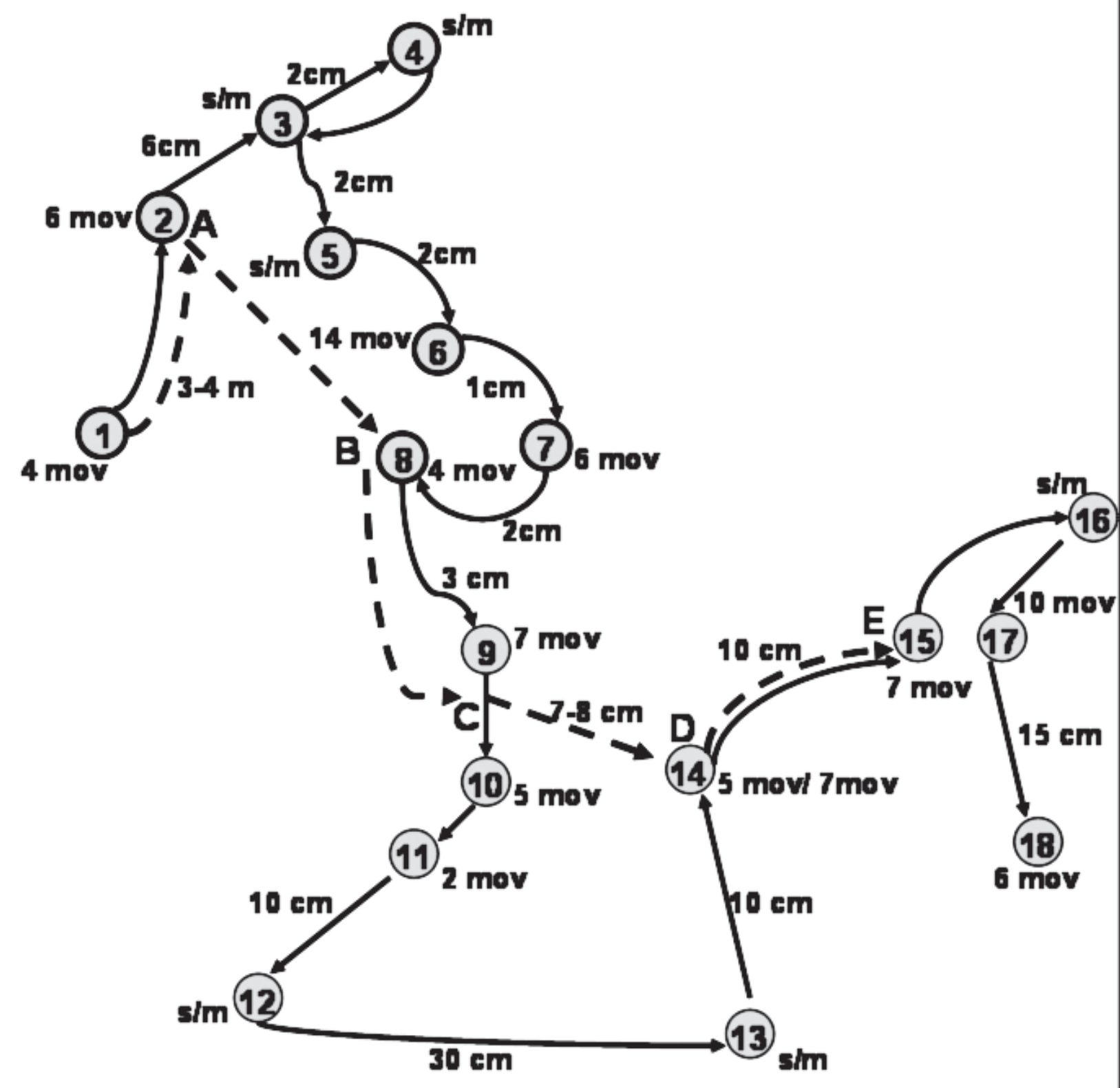

